\title{
PREFACE - ISPRS WORKSHOP INDOOR 3D 2019
}

\author{
Zhizhong Kang ${ }^{1}$, Kourosh Khoshelham², Lucía Díaz-Vilariño ${ }^{3}$, and Sagi Dalyot ${ }^{4}$ (Editors, Indoor 3D) \\ ${ }^{1}$ China University of Geosciences, Beijing, China \\ ${ }^{2}$ Department of Infrastructure Engineering, The University of Melbourne, Australia \\ ${ }^{3}$ Applied Geotechnologies Group, Dept. of Natural Resources and Environmental Engineering, University of Vigo, Spain \\ ${ }^{4}$ Technion - Israel Institute of Technology, Technion City, Haifa 3200003, Israel
}

Indoor 3D 2019 is the 4th event of a series of biannual ISPRS workshops focusing on research and developments in the area of indoor spatial information, aiming to promote international state-of-the-art research and facilitating dialogue on emerging topics. The Indoor 3D 2019 workshop brings together researchers, professionals and users from the academia and industry involved in indoor and outdoor mapping, positioning, tracking, navigation, 3D modeling, location-based services and mobility. Topics include Seamless indoor/outdoor 3D modelling and mapping, Indoor localization and route planning, visual positioning and SLAM methods in indoor environments, semantic parsing in indoor environments, indoor virtual/augmented reality, quality aspects and evaluation of indoor models.

The Indoor 3D workshop was organized in conjunction with other workshops during the ISPRS Geospatial Week 2019 in Enschede, The Netherlands, in cooperation with ISPRS WG I/6 (Multi-sensor Integration and Fusion), ISPRS WG I/7 (Mobile Mapping Technology), ISPRS ICWG I/IV (Robotics for Mapping and Modelling), and OGC IndoorGML Standards Working Group.

A total of 43 submissions was received by the workshop and entered the review process by the scientific and organizing committees: 29 abstract submissions and 14 full submissions. Given the review results, 34 submissions were accepted as contributions for presentation and inclusion in the proceedings, according to this division: 9 ISPRS Annals for oral presentation, 21 ISPRS Archives for oral presentation, and 3 ISPRS Archives for poster presentation. The selection in favor of ISPRS Annals publication was made based on the scientific originality and impact of the manuscript as judged by both the reviewers and the organizing committee. All submissions accepted for publication contain novelty and stimulating new scientific ideas. We wish to thank all the authors for their effort and contribution, and all the reviewers for their time, valuable comments and their inspiring help in evaluating the manuscripts, which contributed to the high quality of the papers presented in Indoor 3D 2019.

\section{Organizing Committee, Indoor 3D 2019}

Zhizhong Kang, Kourosh Khoshelham, Lucía Díaz-Vilariño, Cheng Wang, Stephan Nebiker, Ville Lehtola, Kai-Wei Chiang, Ki-Joune Li, Bart De Lathouwer, Sagi Dalyot

\section{Scientific Committee, Indoor 3D 2019}

$\begin{array}{llll}\text { Abdoulaye Diakite } & \text { Eric Guilbert } & \text { Marco Scaioni } & \text { Qing Zhu } \\ \text { Antonio Adán } & \text { Filip Biljecki } & \text { Markus Gerke } & \text { Ruisheng Wang } \\ \text { Ben Gorte } & \text { Fuqiang Gu } & \text { Martin Kada } & \text { Sergio Ilarri } \\ \text { Beril Sirmacek } & \text { George Sithole } & \text { Masafumi Nakagawa } & \text { Sisi Zlatanova } \\ \text { Chenglu Wen } & \text { Iván Puente } & \text { Mattia Previtali } & \text { Thomas Kolbe } \\ \text { Christophe Claramunt } & \text { Hiroyuki Miyazaki } & \text { Mohsen Kalantari } & \text { Umit Isikdag } \\ \text { David Sánchez Rodríguez } & \text { Jianga Shang } & \text { Muhammad Cheema } & \text { Youness Dehbi } \\ \text { Derek Lichti } & \text { Joaquín Martinez Sánchez } & \text { Pawel Boguslawski } & \text { Zhiyong Wang } \\ \text { Edward Verbree } & \text { Ken Arroyo Ohori } & \text { Peter Wonka } & \end{array}$

